\title{
Peningkatan Kualitas Manufaktur Produk Circuit Breaker-Arc Chute
}

\author{
HARI SUPRIYANTO, M. FERDIAN RAHMA SUPRIYANTO \\ Departemen Teknik dan Sistem Industri, Fakultas Teknologi Industri \\ Institut Teknologi Sepuluh Nopember - ITS Surabaya \\ Email: hariqive@yahoo.com
}

Received 3 Desember 2019 | Revised 30 Februari 2020 | Accepted 6 Mei 2020

\begin{abstract}
ABSTRAK
Sektor industri kecil dan menengah (IKM) berkontribusi cukup besar dalam perkembangan perekonomian Indonesia. Salah satu IKM yang bergerak di sektor ini adalah usaha circuit breaker. Mereka memiliki permasalahan defect produk. Lean sixsigma dipakai sebagai pendekatan improvement yang bertujuan untuk meningkatkan kualitas dengan cara mengurangi variasi produk. Tiga alternatif solusi, yaitu pelatihan staff, pengadaan fasilitas, dan modifikasi fasilitas. Alternatif perbaikan yang paling optimal untuk setiap proses adalah pelatihan untuk karyawan blanking dan pelatihan untuk karyawan electroplating. Alternatif perbaikan yang dipilih selanjutna diterapkan dengan tujuan meningkatkan sigma level dan mengurangi biaya kualitas. Penerapan alternatif menunjukkan kenaikan nilai sigma untuk proses blanking dari 3.96 sigma menjadi 4.05 sigma. Sedangkan untuk proses electroplating terjadi kenaikan nilai sigma dari 3.20 sigma menjadi 3.51 sigma.
\end{abstract}

Kata kunci: lean, waste, Sixsigma, defect, RCA, FMEA

\begin{abstract}
The industrial sectors of small and medium enterprises (SMES) have a considerable contribution to economic development in Indonesia. One SMEs engaged in the business sector is the circuit breaker. The main problem occurs the defected product is quite high and needs improvement, to increase product quality. Lean six sigma is used as improvement approach aimed at improving quality by reducing the variety of products. There are three alternative solutions, namely the training of staff, the purchase of the facility, and modification of the facility. The most optimal alternative for each process is blanking worker training and electroplating worker training. Training in both processes, then applied to increase sigma levels and reduce quality costs. Alternative implementations showed an increasing sigma value for blanking process from 3.96 sigma becomes 4.05 sigma. As for the electroplating process an increasing rate from 3.20 sigma becomes 3.51 sigma.
\end{abstract}

Keywords: lean, waste, Sixsigma, defect, RCA, FMEA 
Peningkatan Kualitas Manufaktur Produk Circuit Breaker-Arc Chute

\section{PENDAHULUAN}

Banyak perusahaan kecil di sekitar kita sekelas IKM yang harus bersaing ketat untuk mendapatkan pasar. Satu faktor yang harus diperhatikan adalah berkomitmen untuk meningkatkan kualitas produk (Antony, 2011) (James, 2007). Produk yang menjadi unggulan adalah arc chute, yang disuplai untuk Perusahaan Electric. Arc chute tersusun dari 2 jenis komponen, yaitu arc chute plate dan fiber. Material yang digunakan dalam pembuatan arc chute plate adalah plat logam berbahan nikel (nickel metal sheet), sedangkan untuk fiber menggunakan lembaran fiber (fiber sheet). Pembuatan arc chute plate mulai dari pemotongan material, punching, hingga electroplating. Pembuatan fiber hanya melalui 2 proses, yaitu proses pemotongan material dan punching. Kedua komponen ini dikirim ke departemen perakitan untuk dirakit menjadi produk arc chute. Diketahui bahwa komponen arc chute mempunyai jumlah defect dengan kontribusi sebesar lebih dari $9 \%$ dari total produksi. Bersamaan dengan tinggnya komponen cacat, maka jumlah komponen yang harus diproduksi akan semakin banyak pula (Darshak, 2017).

Kontribusi industri kecil dan menengah (IKM) dalam perkembangan perekonomian Indonesia cukup besar, ini dapat dilihat di Jawa Timur yang $73.51 \%$ nilai produksi industri dikuasai oleh industri kecil dan menengah (Kementrian Perindustrian, 2019). Peningkatan permintaan produk berkualitas tinggi oleh perusahaan besar memaksa IKM untuk memperhitungkan implementasi peningkatan kualitas secara terus menerus dalam strategi bisnisnya (Albliwi, dkk, 2015)(Timans, dkk, 2016). Selama ini IKM di Indonesia mempunyai kendala dalam memenuhi spesifikasi agar mencapai standar yang telah ditetapkan. Persoalan ini mendorong IKM untuk meningkatkan kualitasnya, baik dari segi produk, pelayanan, ataupun organisasi. Kualitas sendiri dapat diartikan sebagai tingkat atau kesesuaian suatu produk dengan pemakainya, dalam arti sempit kualitas diartikan sebagai tingkat kesesuaian produk dengan standar yang telah ditetapkan.

Six Sigma merupakan suatu pendekatan improvement yang bertujuan untuk mencari dan mengeliminasi penyebab kesalahan atau defect dalam proses bisnis dan fokus pada output proses yang kritis bagi konsumen. Six Sigma dikenal sebagai metode peningkatan kualitas yang paling efektif, dan penggunaannya menunjukkan tren positif (Darshak, 2017). Meskipun Six Sigma telah diimplementasikan dengan sukses di berbagai perusahaan besar, masih sedikit dokumentasi kesuksesan implementasi metode ini di organisasi yang lebih kecil (Antony, 2011). Salah satu keunggulan utama dari Six Sigma adalah kemampuan untuk menyajikan ukuran kualitas dari perspektif konsumen, yang dapat diaplikasikan pada berbagai ukuran dan macam organisasi. Keberhasilan upaya Motorola tidak hanya mencapai tingkat kualitas six sigma, tetapi fokusnya adalah pada pengurangan cacat produk dalam proses melalui pemanfaatan seluruh alat dan teknik statistik. Ini akan mengarah pada peningkatan kualitas layanan, meningkatkan produktivitas dan kepuasan pelanggan, mengurangi biaya operasi atau biaya kualitas buruk, dan sebagainya. Six-sigma, sebagai metodologi peningkatan kualitas, telah mendapatkan perhatian yang cukup besar (Chakraborty \& Tan, 2004). Penerapan metode six-sigma memungkinkan organisasi untuk mempertahankan keunggulan kompetitif dengan mengintegrasikan proses dengan teknik, statistik dan manajemen proyek (Zagloel, dkk, 2018). Banyak artikel dan buku yang memberikan konsep dasar dan manfaat dari metode six-sigma (Anbari, dkk, 2004)(Dhiraj \& Deepak, 2014). Aplikasi Six-Sigma di sektor layanan masih terbatas meskipun telah dianut oleh banyak perusahaan berorientasi layanan besar seperti Lloyd, American Express, JP Morgan, ESB, Telur, Layanan Keuangan, Zurich, BT dll. Dekade terakhir telah melihat banyak organisasi layanan seperti Bank of 
America, Citibank, Caterpillar, Mount Carmel Health System dan Baxter Healthcare di AS dan Eropa, sukses dengan penerapan six sigma (Albliwi, dkk, 2015) (Jiju, 2002) (Master of Science in Management Engineering, 2014).

Tabel 1. Savings and Benefits dari Six-Sigma dalam Sektor Manufaktur

\begin{tabular}{|c|c|c|}
\hline Company/ project Metric & measures Benefit & savings \\
\hline Motorola (1992) & In-process defect levels & 150 times reduction \\
\hline Raytheon/aircraft integration systems & Depot maintenance inspection time & Reduced $88 \%$ as measured in days \\
\hline GE/ Railcar leasing business & Turnaround time at repair shops & $62 \%$ reduction \\
\hline $\begin{array}{l}\text { Allied signal (Honeywell)/laminates plant } \\
\text { in South Carolina }\end{array}$ & $\begin{array}{l}\text { Capacity Cycle time Inventory On- } \\
\text { time delivery }\end{array}$ & $\begin{array}{l}\text { Up } 50 \% \text { Down } 50 \% \text { Down } 50 \% \\
\text { Increased to near } 100 \%\end{array}$ \\
\hline $\begin{array}{l}\text { Allied signal (Honeywell)/bendix IQ brake } \\
\text { pads }\end{array}$ & Concept-to-shipment cycle time & Reduced from 18 months to 8 months \\
\hline $\begin{array}{l}\text { Hughes aircraft's missiles systems } \\
\text { group/wave soldering operations }\end{array}$ & Quality/productivity & Improved $1,000 \% /$ improved $500 \%$ \\
\hline General electric & Financial & $\$ 2$ billion in 1999 \\
\hline Motorola (1999) & Financial & $\$ 15$ billion over 11 years \\
\hline Dow chemical/rail delivery project & Financial & $\begin{array}{l}\text { Savings of } \$ 2.45 \text { million in capital } \\
\text { expenditures }\end{array}$ \\
\hline DuPont/Yerkes plant in New York (2000) & Financial & savings of more than $\$ 25$ million \\
\hline Telefonica de espana (2001) & Financial & $\begin{array}{l}\text { Savings and increases in revenue } 30 \\
\text { million euro in the first } 10 \text { months }\end{array}$ \\
\hline Texas instruments & Financial & $\$ 600$ million \\
\hline Johnson and Johnson & Financial & $\$ 500$ million \\
\hline Honeywell & Financial & $\$ 1.2$ billion \\
\hline
\end{tabular}

Sumber:(Ir, dkk, 2010) (Jiju, 2002) (Master of Science in Management Engineering, 2014)

Untuk menemukan akar permasalahan (root causes) diterapkan DMAIC (define, measure, analyze, improve, contro). Hasil akhir dari penelitian ini adalah rekomendasi perbaikan kualitas proses produksi. Rekomendasi perbaikan biasanya membutuhkan biaya yang berkaitan dengan perubahan teknologi, modifikasi peralatan yang ada, pelatihan pegawai, perekrutan pegawai baru, dan investasi infrastruktur teknologi informasi (Timans, dkk, 2016). Alternatif perbaikan ini diterapkan untuk meningkatkan sigma leve/dan mengurangi biaya kualitas. Akan tetapi perlu diperhatikan bahwa keuntungan marginal dari proyek Six Sigma manapun akan berkurang seiring dengan meningkatnya sigma quality level. Perbaikan pada sigma leve/yang lebih tinggi tinggi membutuhkan biaya dan usaha yang jauh lebih besar daripada perbaikan pada sigma level yang rendah. Pendekatan Lean dengan Six sigma dapat diterapkan untuk memperbaiki kualitas dan sistem produksi yang sedang berjalan. Pendekatan Lean Six Sigma ini untuk membantu pihak manajemen dalam pemilihan alternatif perbaikan.

Penelitian ini bertujuan untuk menanggulangi permasalahan defect dengan menggunakan metode Lean Six Sigma.

\section{METODE PENELITIAN}

Siklus Six-Sigma dipakai untuk membangun continous process improvement. Siklus yang dipakai adalah Define, Measure, Analysis dan Contro/ seperti ditunjukkan pada Gambar 1. 


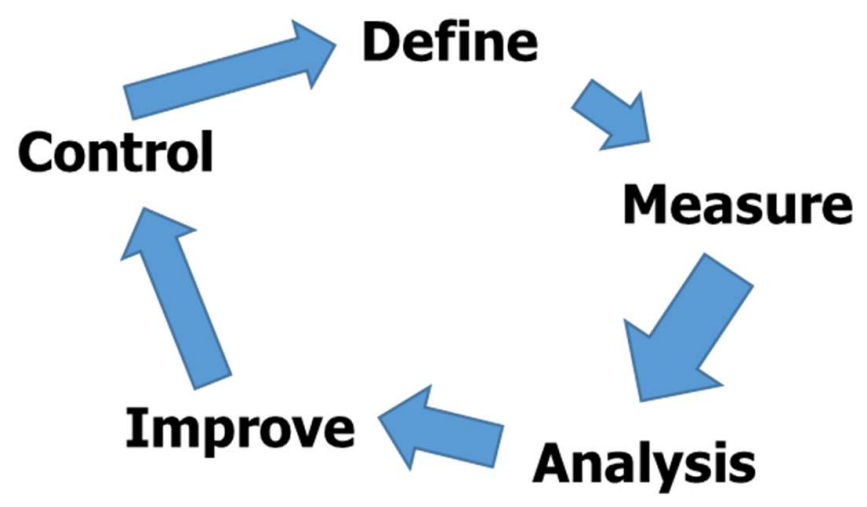

Gambar 1. Siklus Six Sigma

Metoda yang dipakai untuk menentukan problem adalah dalam bentuk waste (pemborosan). Yang menjadi acuan untuk perbaikan adalah pendekatan lean thinking. Lean manufacturing merupakan pendekatan sistematis untuk mengidentifikasi dan mengeliminasi waste melalui perbaikan yang berlanjut dari produk untuk memenuhi permintaan konsumen secara sempurna. Paradigma lean thinking dapat dengan mudah membedakan antara pemborosan dan nilai tambah di sepanjang proses produksi. Pemborosan (waste) adalah setiap aktivitas yang menyerap sumber daya tetapi tidak menciptakan nilai tambah. Nilai didefinisikan sebagai kemampuan perusahaan untuk membuat produk atau layanan, yang diberikan kepada pelanggan, mempunyai fungsi yang tepat, pengiriman tepat waktu, jumlah yang tepat dan harga yang sesuai. Lean thinking in action adalah identifikasi dan penghapusan pemborosan yang dilakukan terus menerus dan hanya menyisakan kegiatan bernilai tambah di sepanjang aliran nilai (Chahal \& Narwal, 2017)(Hill dkk, 2018). Setiap tindakan untuk mengidentifikasi dan menghilangkan pemborosan adalah karakteristik dari paradigma lean thinking.

Lean manufacturing adalah suatu strategi untuk dapat berproduksi pada level yang tinggi dengan persediaan yang minimal. Eight waste dipilih untuk menjadi runutan mencari critical waste. Delapan waste yang dipakai untuk mengidentifikasi permasalahan adalah Environment healty and safety waste, defect waste, over production waste, waiting waste, not utilize employee waste, transportation waste, inventor waste, motion waste dan excessive processing. Waste dapat diidentifikasikan sebagai idle time yang terjadi selama proses terjadi dan tidak mempunyai nilai tambahnya. Strategi yang benar dari lean manufacturing adalah dapat mengurangi biaya dan meningkatkan kualitas. Kekuatan dari kedua konsep ini disinergikan menjadi satu konsep yang tertintegrasi yaitu Konsep Lean Six Sigma (Antony, 2011)(Supriyanto \& Maftuhah, 2017). 


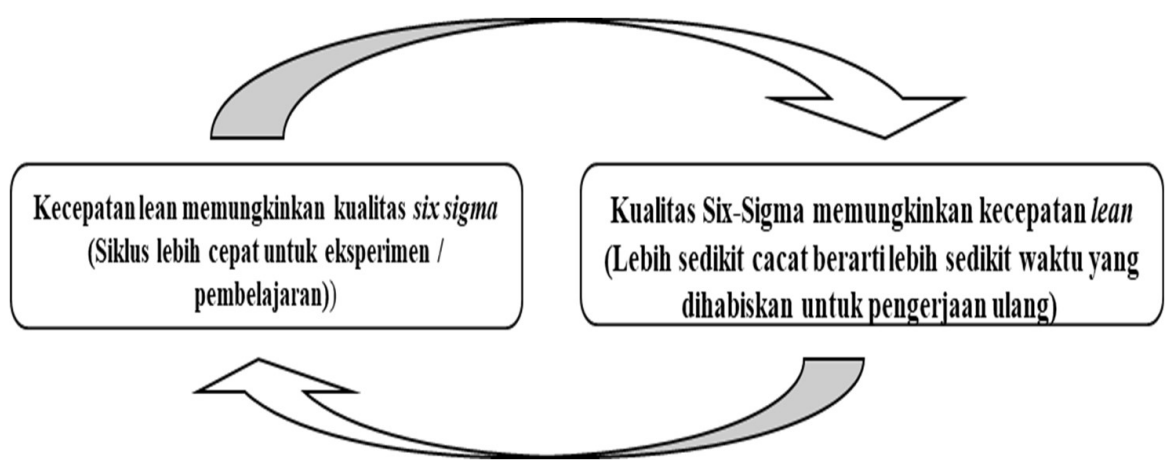

Gambar 2. Keterkaitan Lean dan Six Sigma

Pemikiran Lean Six Sigma perlu disebarluaskan ke seluruh bagian tanpa memandang tipe industri atau tipe kegiatan (George, 2003). Dengan demikian Lean Six Sigma dapat diterapkan dalam semua proses. Lean Six Sigma yang diterapkan dalam industri manufaktur akan menjadi Lean Six Sigma Manufacturing; kedua konsep dapat dilihat pada Gambar 2.

Tahapan terpenting adalah mencari penyebab munculnya critical to quality (CTQ) yang merupakan problem utama. Tools yang digunakan adalah Roots Cause Analysis-RCA (Andersen \& Fagerhaug, 2006)(Rooney \& Vanden Hauvel, 2004). Tools ini dipakai mirip dengan fish bone diagram. Tujuan utamanya adalah mengidentifikasi seluruh kemungkinan causes yang mungkin dan timbul dari masalah yang sedang dihadapi. RCA mendeploy masalah dengan menanyakan why sampai 5 (lima) tingkatan. Tools lainnya adalah FMEA (Failure Mode and Effect Analysis). Setelah itu dilakukan penyusunan rancangan perbaikan untuk mengurangi kegagalan pada proses. FMEA digunakan untuk mengidentifikasi tindakan-tindakan korektif. Hasil akhir dari FMEA adalah Risk Priority Number (RPN). RPN adalah hasil perkalian dari Severity (s); Occurance (o) dan Detection (D). Penetapan usulan perbaikan didasarkan pada nilai Risk Priority Number (RPN) tertinggi (Sutrisno, dkk, 2014).

\section{HASIL DAN PEMBAHASAN}

Arc chute merupakan bagian penting dari circuit breaker modern. Gambar 3 Komponen dan cara kerja dari produk arc chute dalam memilah, mendinginkan, dan menjauhkan percikan dari kontak dalam circuit breaker. Percikan yang dipilah dan dijauhkan dari kontak, mempunyai tujuan untuk membuat usia kontak akan menjadi lebih panjang. Arc chute menyerap 80\% energi yang dikeluarkan saat terjadi interupsi. Seperti terlihat di Gambar 3, produk circuit breaker arc chute di design sedemikian rupa bentuk dan karakteristiknya untuk memenuhi fungsinya.

Secara umum, Arc chute tersusun dari 2 jenis komponen, yaitu arc chute plate dan fiber. Material yang digunakan dalam pembuatan arc chute plate adalah plat besi (mild metal sheet). Pembuatan arc chute plate melalui beberapa proses, mulai dari pembuatan dies, blanking, hingga electroplatting. 

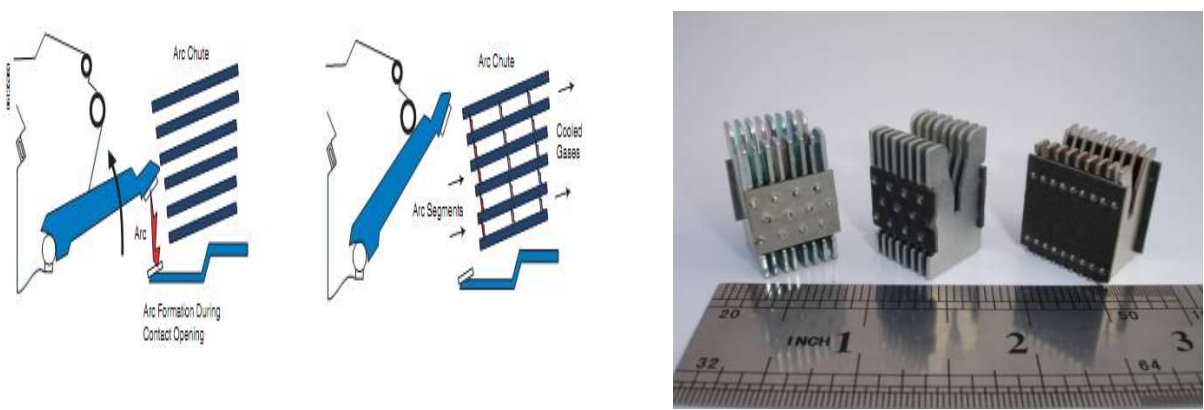

\section{Gambar 3. Komponen Arc Chute}

Cacat produk yang terjadi dapat berupa scrap atau rework. Scrap/ defect adalah cacat yang tidak dapat diproses ulang, dan hasilnya langsung dibuang. Rework adalah cacat yang masih dapat diproses ulang untuk diperbaiki dan dapat dipakai. Cacat yang termasuk rework antara lain cacat permukaan dan cacat assembly. Cacat permukaan merupakan cacat akibat kesalahan proses electroplating, dimana terjadi spot atau noda pada permukaan. Cacat assembly merupakan cacat karena kesalahan pada proses perakitan, pemasangan fiber yang terbalik, kecenderungannya adalah karena operator. Proses produksi dari komponen arc chute dapat diGambarkan dalam bentuk Big Picture Mapping (BPM), seperti terlihat pada Gambar 4, di bawah ini (Albliwi, dkk, 2015).

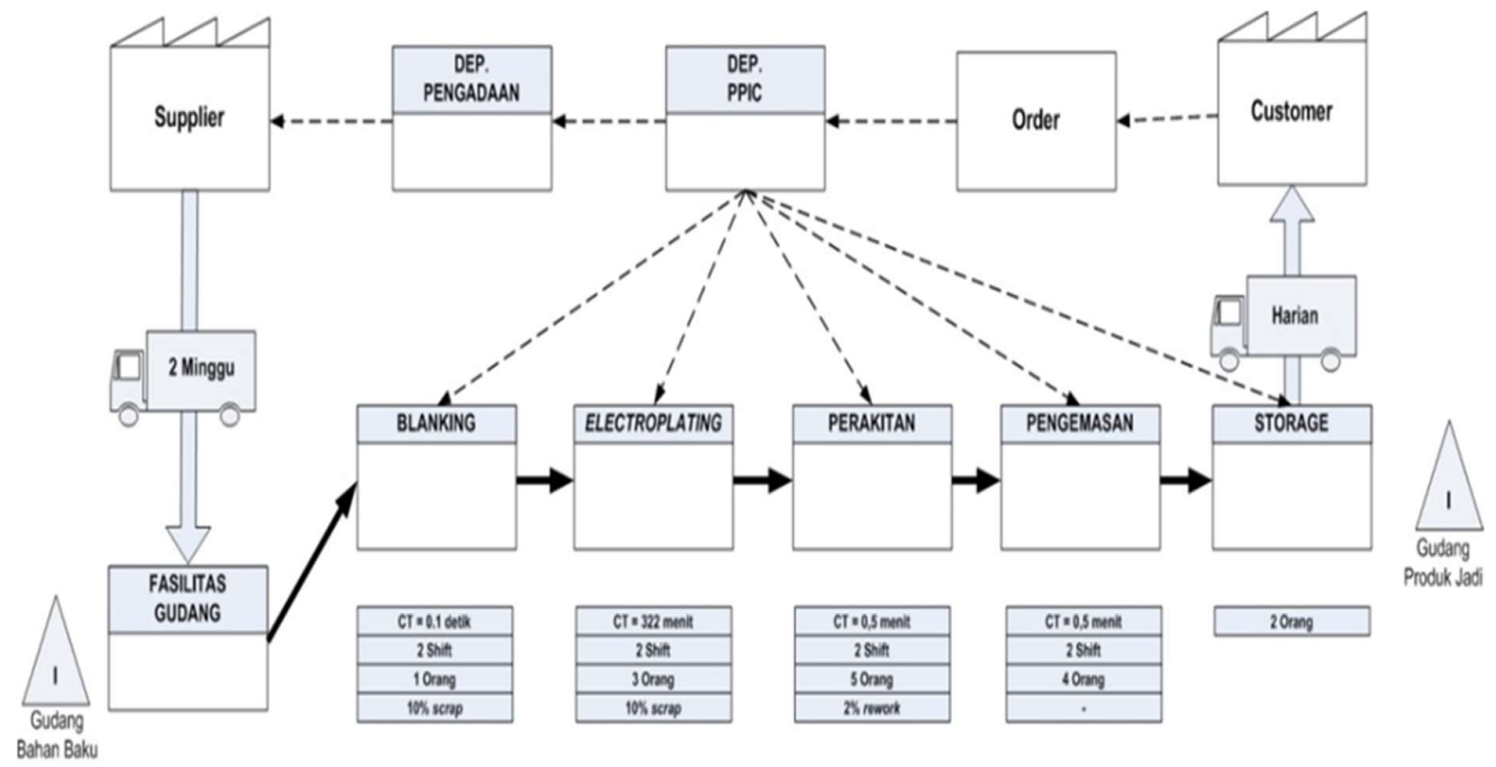

Gambar 4. Big Picture Mapping untuk Proses Produksi Arc Chute Plate

Secara umum big picture mapping menggambarkan urutan proses mulai dari pesanan produk datang sampai produk tersebut ke tangan konsumen. Proses produksi akan terlihat di bagian tengah-bawah. Dengan adanya penggambaran big picture mapping ini menyebabkan identifikasi permasalahan di sepanjang proses dapat diketahui dengan mudah.

Terdapat beberapa jenis defect yang terjadi dalam proses produksi arc chute plate. Jenis defect terdiri dari 5 jenis defect, yaitu terpotong, spot/ noda, tergores, berkarat, dan bengkok. 
CTQ adalah karakteristik kritis yang dapat mempengaruhi kualitas produk. Dengan kata lain CTQ merupakan atribut yang bersentuhan langsung dengan kebutuhan dan kepuasan pelanggan, sehingga menjadi fokus utama untuk melakukan improvement. Proses yang diamati adalah proses blanking dan electroplating.

Tabel 2. Jenis Defect pada Proses Blanking dan Elektoplating

\begin{tabular}{|l|l|l|l|l|}
\hline $\begin{array}{l}\text { Jenis defect } \\
\text { pada proses } \\
\text { blanking }\end{array}$ & $\begin{array}{l}\text { Rata-Rata Defect } \\
\text { per jumlah produksi }\end{array}$ & $\begin{array}{l}\text { Jenis defect pada } \\
\text { proses } \\
\text { elektroplating }\end{array}$ & $\begin{array}{l}\text { Rata-Rata Defect } \\
\text { per jumlah } \\
\text { produksi }\end{array}$ \\
\hline Tergores & 0,0002 & & 0,0344 \\
\hline Terpotong & 0,0074 & Spot & 0,0004 \\
\cline { 1 - 1 } Bengkok & 0,0061 & Berkarat & 0,0551 \\
\hline
\end{tabular}

Setelah macam dan jumlah defect proses blanking dan electroplating untuk setiap jenis defect diidentifikasi. Terdapat dua jenis defect yang kritis pada proses blanking, yaitu terpotong dan bengkok. Kedua jenis defect ini yang menjadi CTQ proses blanking. Selanjutnya dihitung nilai kapabilitas dengan menghitung nilai sigma. Berikut perhitungan nilai sigma untuk proses blanking arc chute plate.

Tabel 3. Perhitungan Nilai Sigma Proses Blanking dan Proses Electroplating

\begin{tabular}{|l|l|l|l|c|}
\hline Proses Blanking & Nilai & & $\begin{array}{l}\text { Proses } \\
\text { Electroplating }\end{array}$ & Nilai \\
\hline $\begin{array}{l}\text { Defect per jumlah } \\
\text { produksi }\end{array}$ & 0,0138 & $\begin{array}{l}\text { Defect per jumlah } \\
\text { produksi }\end{array}$ & 0,0899 \\
\hline Jumlah CTQ & 2 & Jumlah CTQ & 2 \\
\hline DPMO & 6.900 & DPMO & 44.950 \\
\hline Nilai sigma & 3,96 & Nilai sigma & 3,20 \\
\hline
\end{tabular}

Tabel di atas menunjukkan bahwa yang dihasilkan oleh proses blanking lebih bagus dibandingkan dengan proses electroplating. Ini menunjukkan bahwa proses electroplating menghasilkan produk baik lebih banyak dibandingkan dengan proses blanking. Dengan cara yang sama pada proses electroplating diidentifikasi, dan diperoleh CTQ.

Terdapat dua jenis defect yang kritis pada proses electroplating, yaitu bengkok dan spot. Kedua jenis defect ini adalah CTQ di proses electroplating. Langkah selanjutnya adalah menggunakan metode RCA (roots cause analysis) dipakai untuk menelusuri faktor-faktor penyebab defect kritis (Andersen \& Fagerhaug, 2006). RCA merupakan metode untuk mencari akar penyebab permasalahan dan digunakan penelusuran 5 Why. 
Tabel 4. Hasil Penilaian RPN (Risk Priority Number) Untuk Spot

\begin{tabular}{|c|c|c|c|c|c|c|c|c|}
\hline $\begin{array}{l}\text { Jenis } \\
\text { defect }\end{array}$ & $\begin{array}{l}\text { Potential } \\
\text { Failure } \\
\text { Mode }\end{array}$ & Effect & Severity & Cause & $\begin{array}{c}\text { Occuren } \\
\text { ce }\end{array}$ & Control & $\begin{array}{l}\text { Detec } \\
\text { tion }\end{array}$ & RPN \\
\hline \multirow{4}{*}{ Spot } & \multirow[t]{2}{*}{$\begin{array}{l}\text { Umur mesin } \\
\text { pelapisan } \\
\text { sudah tua }\end{array}$} & \multirow[t]{2}{*}{$\begin{array}{c}\text { Terbentuk } \\
\text { noda hangus } \\
\text { di permukaan } \\
\text { arc chute } \\
\text { plate }\end{array}$} & 6 & $\begin{array}{l}\text { Akurasi } \\
\text { tegangan } \\
\text { mesin } \\
\text { rendah }\end{array}$ & 3 & $\begin{array}{l}\text { Setup } \\
\text { mesin }\end{array}$ & 5 & 90 \\
\hline & & & 6 & $\begin{array}{c}\text { Indikator } \\
\text { voltmeter } \\
\text { dan } \\
\text { amperemete } \\
\text { r masih } \\
\text { menggunaka } \\
\mathrm{n} \text { analog }\end{array}$ & 3 & $\begin{array}{l}\text { Analisis } \\
\text { lebih } \\
\text { lanjut }\end{array}$ & 5 & 90 \\
\hline & \multirow[t]{2}{*}{$\begin{array}{l}\text { Kesalahan } \\
\text { SOP dalam } \\
\text { proses } \\
\text { pelapisan arc } \\
\text { chute plate }\end{array}$} & $\begin{array}{c}\text { Terbentuk } \\
\text { noda hangus } \\
\text { di permukaan } \\
\text { pelat }\end{array}$ & 6 & $\begin{array}{c}\text { Jumlah arc } \\
\text { chute plate } \\
\text { yang } \\
\text { diproses } \\
\text { terlalu } \\
\text { banyak }\end{array}$ & 3 & $\begin{array}{l}\text { Analisis } \\
\text { lebih } \\
\text { lanjut }\end{array}$ & 6 & 108 \\
\hline & & $\begin{array}{l}\text { Permukaan } \\
\text { arc chute } \\
\text { plate tidak } \\
\text { rata }\end{array}$ & 5 & $\begin{array}{c}\text { Proses } \\
\text { penyimpana } \\
\text { n WIP tidak } \\
\text { sempurna }\end{array}$ & 2 & Visual & 5 & 60 \\
\hline
\end{tabular}

Setelah identifikasi akar penyebab dari setiap jenis defect kritis, tahap selanjutnya adalah mengembangkan failure mode and effect analysis (FMEA). Pada FMEA, masing-masing akar penyebab yang dicari dengan menggunakan metode RCA akan dinilai dari segi severity, occurrence, dan detection (SOD). Penilaian SOD dilakukan oleh ahli di setiap bagian (Okwuobi, dkk, 2018).

Hasil akhir FMEA adalah RPN yang menjadi indikator akar permasalahan mana yang sebaiknya menjadi fokus improvement (Nielsen, 2013). Dari beberapa akar penyebab untuk jenis defect spot, diambil satu cause yang memiliki RPN tertinggi. Moda kegagalan yang pertama adalah umur mesin pelapisan yang sudah tua, dengan nilai RPN (risk priority number) kedua sebesar 90. Moda kegagalan yang kedua adalah kesalahan SOP dalam proses pelapisan arc chute plate dengan nilai RPN (risk priority number) pertama sebesar 108. Jadi untuk pemilihan RPN ini berdasarkan pada resiko tertingginya, yang ditunjukkan dengan nilai RPN tertingginya. Alternatif perbaikannya akan didasarkan pada resiko tertinggi ini. Alternatif perbaikan dirancang untuk mengatasi akar permasalahan dari defect yang terjadi pada komponen arc chute plate.

Pemilihan RPN tertinggi ini mempunyai arti bahwa resiko yang akan ditanggung akan besar bila tidak memakai dasar tertinggi ini untuk membangun alternatif perbaikan. Alternatif perbaikan yang menjadi pegangan untuk dijalankan adalah alternatif yang menyebabkan akar permasalahan timbul. Dengan demikian dapat dipahami bahwa alternatif yang akan dipilih adalah alternatif yang dapat mengurangi defect produk. 
Tabel 5. Alternatif Perbaikan Terhadap Setiap Akar Permasalahan

\begin{tabular}{|l|l|}
\hline \multicolumn{1}{|c|}{ Akar Penyebab } & \multicolumn{1}{c|}{ Alternatif Perbaikan } \\
\hline $\begin{array}{l}\text { Indikator voltmeter dan amperemeter } \\
\text { masih menggunakan indikator analog }\end{array}$ & $\begin{array}{l}\text { Penggantian mesin rectifier dengan mesin yang } \\
\text { memiliki indikator digital }\end{array}$ \\
\hline $\begin{array}{l}\text { Jumlah arc chute plate yang diproses } \\
\text { terlalu banyak }\end{array}$ & $\begin{array}{l}\text { Pengadaan pelatihan untuk staff bagian } \\
\text { electroplating }\end{array}$ \\
\hline $\begin{array}{l}\text { Keranjang penampung tidak didesain } \\
\text { untuk ditumpuk }\end{array}$ & $\begin{array}{l}\text { Penggantian keranjang penampung dengan } \\
\text { stackable plastic crate }\end{array}$ \\
\cline { 2 - 2 } & $\begin{array}{l}\text { Pemberian sekat di antara keranjang } \\
\text { penampung }\end{array}$ \\
\hline Uncoiler tidak diputar oleh operator & Modifikasi uncoiler \\
\hline
\end{tabular}

Dengan adanya akar penyebab dan kemungkinan alternatif yang dapat mengurangi defect, maka diambil alternatif terpilih yang sesuai dengan target dan biaya yang ditetapkan oleh perusahaan. Alternatif tersebut dikatakan berhasil bila terjadi penurunan defect dan akan terjadi kenaikan nilai sigma. Pemilihan alternatif yang menjadi bahan pertimbangan lainnya adalah, 1. Apakah dengan adanya alternatif tersebut menyerap waktu yang akhirnya dapat menurunkan kapasitas produksi, 2. Perlu dipertimbangkan bagaimana biaya yang muncul untuk melakukan alternatif terpilih.

Bila alternatif perbaikan 1 yaitu pelatihan untuk staff untuk proses blanking maupun electroplating, dan alternatif ini dapat menurunkan fraksi defect dan meningkatkan nilai sigma maka alternatif ini adalah merupakan indikator yang baik dan benar, bahwa mampu meningkatkan kapabilitas proses untuk proses blanking ataupun electroplating seperti terlihat di Tabel 5.

Dari tabel di atas dapat dilihat bahwa fraksi (f) dari defect mengalami penurunan untuk proses blanking dari kondisi awal sebesar 0,0138 (1,38\%) menjadi 0,0106 (1,06\%). Demikian juga untuk proses Electroplating terjadi penurunan dari kondisi awal 0,0899 (8,99\%) menjadi 0,045 $(4,5 \%)$. Penurunan prosentase dari kecacatan untuk proses Electroplating ini dapat dikatakan sempurna karena penurunannya mendekati $50 \%$, sehingga dapat dikatakan bahwa penurunan tingkat cacat pada proses Electroplating akan menjadi pemicu keberhasilan dalam menginisiasi konsep dan metodologi lean six-sigma.

Tabel 6. Defect per Jumlah Produksi Sebelum dan Sesudah Perbaikan

\begin{tabular}{|l|c|c|c|c|}
\hline \multicolumn{1}{|c|}{ Proses } & $\mathbf{f}_{\mathrm{i} \text { eksisting }}$ & $\mathbf{f}_{\mathrm{i} \text { perbaikan }}$ & $\begin{array}{c}\text { Nilai Sigma } \\
\text { Eksisting }\end{array}$ & $\begin{array}{c}\text { Nilai Sigma } \\
\text { Setelah } \\
\text { Perbaikan }\end{array}$ \\
\hline Blanking & 0,0138 & 0,0106 & 3,96 & 4,05 \\
\hline Electroplating & 0,0899 & 0,0450 & 3,20 & 3,51 \\
\hline
\end{tabular}

Untuk nilai sigma dapat dilihat bahwa untuk proses Blanking dari kondisi awal sebesar 3,96 menjadi 4,05. Demikian juga untuk proses Electroplating terjadi peningkatan nilai sigma dari kondisi awal 3,20 menjadi 3,51. Nilai-nilai dari fraksi cacat dan sigma tersebut menujukkan bahwa alternatif yang dipilih adalah alternatif yang benar, karena dapat menurunkan defect produk dan menaikkan nilai sigma-nya. 
Penurunan tingka cacat sampai mendekati $50 \%$ dari proses Electroplating bila dihubungkan dengan kenailkan nilai sigma, ternyata sigma dari proses Blanking masih lebih bagus dibandingkan dengan nilai sigma dari proses Electroplating. Ini menunjukkan bahwa proses yang berada di dalam Blanking lebih bagus dibandingkan dengan proses yang berada di proses Electroplating. Nilai sigma di proses Blanking sudah mencapai lebih dari 4, tetapi nilai sigma di proses Electroplating berada di bawah 4. Nilai ini yang menyebabkan rework di proses Electroplating menjadi sangat besar.

\section{KESIMPULAN}

Kesimpulan yang dapat diberikan pada penelitian ini adalah:

1. Berdasarkan hasil dari CTQ (Critical to Quality), terdapat dua proses yang menyebabkan defect yaitu proses blanking, dan proses electroplating,

2. Terdapat tiga alternatif solusi, yaitu pelatihan staff, pengadaan fasilitas, dan modifikasi fasilitas.

3. Alternatif perbaikan yang optimal adalah pelatihan untuk staff blanking dan electroplating.

4. Level sigma proses diketahui terjadi kenaikan untuk proses blanking dari 3.96 sigma menjadi 4.05 sigma, dan untuk proses electroplating terjadi kenaikan dari 3,20 sigma menjadi 3.51 sigma; ini menunjukkan bahwa terjadi keberhasilan dan positif, dengan indikator adanya penurunan tingkat defect product.

Konsep yang ditawarkan ini adalah sebuah konsep yang sifatnya continuous improvement. Artinya bahwa bila terjadi keberhasilan di suatu pereoda maka untuk pereoda berikutnya tetap dicari dan diidentifikasi waste mana lagi yang harus dikurangi bahkan dihilangkan. Konsep continuous improvement tidak berhenti untuk sekali keberhasilan saja, tetapi keberhasilan terssebut harus dicari terus-menerus, karena satu alasan kuatnya adalah reliability (keandalan) mesin semakin lama menjadi semakin turun. Keandalan inilah yang menjadi alasan mengapa harus continuous improvement.

\section{DAFTAR RUJUKAN}

Albliwi, S., Antony, J., \& Lim, S. (2015). A systematic review of Lean Six Sigma for the manufacturing industry. Business Process Management Journal, 21, 665-691. https://doi.org/10.1108/BPMJ-03-2014-0019

Anbari, F. T., Ph, D., George, T., Kwak, Y. H., Ph, D., \& George, T. (2004). Success Factors in Managing Six Sigma Projects. 1-14.

Andersen, B., \& Fagerhaug, T. (2006). Root Cause Analysis: Simplified Tools and Techniques, Second Edition.

Antony, J. (2011). Six Sigma vs Lean: Some perspectives from leading academics and practitioners. International Journal of Productivity and Performance Management, 60, 185-190. https://doi.org/10.1108/17410401111101494

Chahal, V., \& Narwal, M. S. (2017). Management Science Letters. 7, 321-336. https://doi.org/10.5267/j.msl.2017.4.004

Chakraborty, A., \& Tan, K. C. (2004). Case study analysis of Six Sigma implementation in 
service organisations. https://doi.org/10.1108/14637151211283384

Darshak, D. (2017). Competitive advantage through Six Sigma at plastic injection molded parts manufacturing unit: A case study. International Journal of Lean Six Sigma, 8(4), 411435. https://doi.org/10.1108/IJLSS-06-2016-0022

Dhiraj, K., \& Deepak, K. (2014). A REVIEW OF SIX SIGMA APPROACH: METHODOLOGY, OBSTACLES AND. 3(4), 1-5.

George, M. L. (2003). Lean Six Sigma for Service: How to Use Lean Speed and Six Sigma Quality to Improve Services and Transactions. In Group. https://doi.org/10.1036/0071436359

Hill, J., Thomas, A. J., Mason-Jones, R. K., \& El-Kateb, S. (2018). The implementation of a Lean Six Sigma framework to enhance operational performance in an MRO facility. Production \& Manufacturing Research, 6(1), 26-48. https://doi.org/10.1080/21693277.2017.1417179

Ir, V., Aktualijos, T., Darbai, M., \& Goh, T. N. (2010). CURRENT ISSUES OF BISINESS AND Paradigm shifts in modern approach to quality excellence. 1-6.

James, R. (2007). Koleksi Buku 2007 Evans, James R. "An introduction to six sigma \& process improvement: pengantar six sigma / James R . Evans, William M . Lindsay "2007. 2007.

Jiju, A. (2002). Key ingredients for the effective implementation of Six Sigma program. Measuring $\quad$ Business 20-27. https://doi.org/10.1108/13683040210451679

Kementrian Perindustrian. (2019). Laporan Kinerja Kementrian Perindustrian Tahun 2018. 1100.

Master of Science in Management Engineering. (2014). December.

Nielsen, J. S. (2013). Risk-Based Operation and Maintenance of Offshore Wind Turbines. https://doi.org/10.13052/rp-9788793102521

Okwuobi, S., Ishola, F., Ajayi, O., Salawu, E., Aworinde, A., Olatunji, O., \& Akinlabi, S. A. (2018). A reliability-centered maintenance study for an individual section-forming machine. Machines, 6(4). https://doi.org/10.3390/machines6040050

Rooney, J. J., \& Vanden Hauvel, L. N. (2004). Root cause analysis for beginners. Quality Progress, 377), 45-53.

Supriyanto, H., \& Maftuhah, D. I. (2017). A lean six-sigma manufacturing process case study. International Journal of Mechanical Engineering and Technology, 8(7), 498-509.

Sutrisno, A., Kwon, H. M., Lee, T.-R. (Jiun-S., \& Ae, J. H. (2014). Improvement Strategy Selection in FMEA - Classification, Review and New Opportunity Roadmaps. Operations 
and Supply Chain Management: An International Journal, 6(2), 54. https://doi.org/10.31387/oscm0140088

Timans, W., Ahaus, K., van Solingen, R., Kumar, M., \& Antony, J. (2016). Implementation of continuous improvement based on Lean Six Sigma in small- and medium-sized enterprises. Total Quality Management \& Business Excellence, 27(3-4), 309-324. https://doi.org/10.1080/14783363.2014.980140

Zagloel, Y., Ardi, R., \& Poncotoyo, W. (2018). Six sigma implementation model based on critical success factors (CSFs) for indonesian small and medium industries. MATEC Web of Conferences, 218, 4017. https://doi.org/10.1051/matecconf/201821804017 